\title{
Bullous skin eruption associated with carbamazepine overdosage
}

\author{
DAVID J. GODDEN* \\ M.B., Ch.B., M.R.C.P. (UK)
}

\author{
JAMES L. MCPHIE \\ M.B., Ch.B., M.R.C.Path
}

Raigmore Hospital, Inverness IV2 3UJ

\begin{abstract}
Summary
A patient who developed a bullous skin eruption associated with carbamazepine overdosage is described. The authors believe this previously unreported phenomenon to be of clinical importance. Carbamazepine should be considered in the differential diagnosis of drug-induced coma with associated bullous lesions.
\end{abstract}

KEY WORDS: carbamazepine overdose, bullous skin eruption.

\section{Introduction}

Bullous skin lesions have been described in association with barbiturate-induced coma (Beveridge and Lawson, 1965) and also with several other drugs (Anonymous, 1981). The lesions characteristically occur at sites of trauma, and within $24 \mathrm{hr}$ of ingesting the drug (Mandy and Ackerman, 1970). The authors wish to report a case of bullous skin eruption as a result of carbamazepine overdosage.

\section{Case report}

A 68-year-old female was brought to the Casualty Department, having been discovered at home in a semi-conscious state. On examination, she was drowsy and disorientated in time and place, her pulse was $90 / \mathrm{min}$ and regular, and the blood pressure was $90 / 70 \mathrm{mmHg}$. There was generalised increase in tone, and hyper-reflexia with equivocal plantar responses bilaterally. Bullous lesions were present on the dorsal aspects of both feet and over the right lower tibia. Further lesions developed over the left iliac crest and on the lateral aspects of the left breast and left forearm during the subsequent $5 \mathrm{hr}$. The lesions varied in size from $0.5 \mathrm{~cm}$ to $3 \mathrm{~cm}$ in diameter, each developing initially as an erythematous patch which progressed within one to $2 \mathrm{hr}$ to form a bulla containing clear fluid and surrounded by a narrow rim of erythema.

\footnotetext{
*Present address: Chest Unit, Papworth Hospital, Cambridge CB3
}

Initial investigation revealed that the urea and electrolytes, arterial blood gas analysis and blood sugar concentration were within normal limits and in barbiturates were not detected in plasma. Following 0 standard supportive therapy, the patient regained full 8 consciousness within the subsequent $24 \mathrm{hr}$. She then $\vec{\omega}$ disclosed that she had been prescribed carbamazep- $\omega_{0}$ ine for facial pain some weeks previously. She hado taken only a few tablets intermittently, until $16 \mathrm{hr} \stackrel{\text { 工 }}{ }$ before admission when she had swallowed approxi- $\bar{z}$ mately 40 tablets. Unfortunately, serum from the time of admission was not available for carbamazepine assay.

Serological examination showed a positive an nuclear factor at a titre of $1 / 640$ and a weakb positive R.A. latex test. The Rose Waaler titre wăs less than 1:4 and DNA binding was 25 units anti$\mathrm{DNA} / \mathrm{ml}$ (reference range-up to 25 units anti-

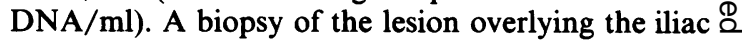
crest was taken and submitted for histological exami- $\overrightarrow{\overrightarrow{0}}$ nation. Direct immunofluorescence study was not $\frac{}{3}$ carried out on the biopsy and indirect examination using the patient's serum was negative. The skin showed an area of subepidermal bulla formation $\overline{0}$ roofed by necrotic epithelium. The dermis was $\underline{3}$. congested with fibrinoid necrosis in an occasional small vessel wall and fibrin and acute inflammatory cells were present.

\section{Discussion}

Carbamazepine is in common usage as an anticonvulsant and in the management of trigeminal $N$ neuralgia. Toxic effects in therapeutic dosage are $N$ relatively common, and skin reactions, including N exfoliative dermatitis, urticaria, Stevens-Johnson syndrome and toxic epidermal necrolysis, are said to occur in 3\% of patients (Crill, 1973; Roberts and $\stackrel{\varrho}{C}$ Marks, 1981). The pattern of reaction occurring in our patient has not, to our knowledge, been previ- + ously documented with carbamazepine overdosage, $\frac{0}{0}$ although a bullous skin eruption has been described $\vec{\Phi}$ with imipramine, a chemically related compound, 
and occasionally in unconscious states without drug ingestion (Freeman and Raza, 1965). A lupus erythematosus-like phenomenon has been described with therapeutic dosage of carbamazepine (Simpson, 1966) and the relationship of therapy to the serological findings in our patient is not clear. However, before the overdose, our patient had taken very few carbamazepine tablets.

We conclude that this patient had subepidermal bullous formation occurring as a result of carbamazepine overdosage, the clinical pattern resembling a barbiturate-induced bullous eruption. Carbamazepine should be considered in the differential diagnosis of drug-induced coma with associated bullous lesions.

\section{Acknowledgment}

We thank Dr John Burton, Consultant Physician, for permission to publish the details of this patient under his care.

\section{References}

ANONYmous (1981) Drug-induced bullous eruptions. British Medical Journal, 282, 421.

BEVERIDGE, G.W. \& LAWSON, A.A.H. (1965) Occurrence of bullous lesions in acute barbiturate intoxication. British Medical Journal, $1,835$.

CRILL, W.E. (1973) Carbamazepine. Annals of Internal Medicine, 79, 844.

Freeman, D.M. \& RaZA, M. (1965) Bullous lesions in a cute barbiturate intoxication (letter) British Medical Journal, 1, 1495.

MANDY, S. \& ACKERMAN, A.B. (1970) Characteristic traumatic skin lesions in drug-induced coma. Journal of the American Medical Association, 213, 253.

ROBERTS, D.L. \& MARKS, R. (1981) Skin reactions of carbamazepine. Archives of Dermatology, 117, 273.

SIMPSON, J.R. (1966) 'Collagen disease' due to carbamazepine (Tegretol). British Medical Journal, 2, 1434.

(Accepted 18 August 1982) 